\title{
A COMPREHENSIVE APPROACH TO EDUCATION AND MANAGEMENT IN THE SYSTEM OF SECURITY
}

\author{
Rumen MARINOV, Stoyko STOYKOV \\ "Vasil Levski" National Military University, Veliko Tarnovo, Bulgaria \\ marinov_r@nvu.bg, sdstoykov@nvu.bg
}

\begin{abstract}
This report discusses the sensitive issue of the quality of decision-making in the security system, facing inevitable transition towards greater professionalism and technological maturity. While applying the basic principle of situational analysis in terms of ,environmental scanning”, realized through a process of ,breaking down” of the environment into certain factors, and gleaning information about their interplay in the direction of their impact, the authors elaborate on the formulation and the applicability of a novel, science-based, long-term state security and defense policy as well as a pertinent strategy for its implementation.
\end{abstract}

\section{Keywords: system of security, risk, education}

\section{Introduction}

National security, as a societal phenomenon, depends heavily on the accurate functioning of a complex public system that requires the adequate perception of the processes and the entities shaping its structure through unity, integrity, interdependence and constructive conflict. The relevant issues of national security incorporate numerous specific problem areas which in their turn relate to many different dimensions: political, economic, social, ethnic, spiritual, military, informational, environmental, etc. Each component alone or in combination with others may prove critical for the welfare and prosperity of the state, but all of them share one characteristic feature: in general, the human factor plays a crucial role in their normal operation and in particular the educational background of the human resources. Therefore, adequate educational background must provide the appropriate level of competences for each of these aspects of national security.
In the post-modern agenda, with the world facing rapid and drastic change, the competent management of any complex organization stands out as a complicated and responsible activity demanding a high level of governance skills based not only on extensive professional experience but also on profound academic acculturation. The universal aspect of the education process in the system of science and research in the field of security creates the best possible opportunities for the attainment of a successful strategic model of philosophy by boosting confidence and pro-active attitude in the trainees, especially when difficult decisions with subsequent heavy responsibilities will be expected from them. Our society is experiencing more and more the lack of security by the force of an imperative and it will require that education and training in the realm of security and defense be drawn from the plane of the previous fruitless political discussions and introduced into a better governance regime. [1] 


\section{Problem of Research}

Needless to say, very often the general public remains deliberately uninformed, because of the specific nature of the activities, of the results, the processes, the mechanisms, etc. in the field of the security but that cuts both ways because it, as a rule, leads to extreme division of public opinion concerning the importance of the objectives pursued and the proper amount of limited resources allocated for their achievement. As one can expect, the criticism of our system of education as a whole can hardly spare the education in the field of security, and without taking into account the responsibilities of each citizen for the security and the interests of the country due to fact that societal advancement can amount to irreversible damage and foster the proliferation of new threats and antinomies between different socially significant entities (based on different distinguishing criteria, such as profession, race, class, etc.) on this basis.

The system of national security protects values, and education teaches this system of values.

\subsection{Research Focus}

For the creation of a good system of education and training in the field of security, we need to answer the question, "What do we want to do with it and why?" The general public should lay down greater efforts towards the achievement of consensus gentium with regard to the vision, mission and objectives of the education in the system of security. The state administration should outline procedures and mechanisms that will respond clearly to the question, „Who, where, how, and when will play role in the education and the training in the system of security?" And it is the high time our society solved the security dilemma by answering the questions about the allocation of limited resources available for education and training in this field.

\subsection{Methodology of Research}

The need for a comprehensive approach to security education seems unequivocal but it requires a practical model not only providing answers to controversial issues but also prioritizing the improvement of the education management system and security training. Only in this way will the question „I ask who?” Will be replaced by „Ask me, I propose my solution to the problem for which I bear my responsibility!"

The need to apply a comprehensive approach to security research strongly correlates with the constant transition in our view of the development of the security sector and the dynamics of the processes taking place in this very ,delicate" interdisciplinary domain of education and science. This entails incessant adaptation both the approaches to its research and the scope of the researchers and the fields from which the new knowledge is formed.

\subsection{General Background of Research}

Application of the comprehensive approach will not displace existing methods or timehonored approaches to security analysis of the social landscape but demands new mindset, and above all, razing the legacy system of education and research serving the interests of security. Leading institutions for education and security research are able to provide unique scientific expertise across a number of priority research areas and support the process of intelligent security management decisions in the development of doctrines and concepts; creation and management of security resources; forming a new organizational culture in the security system and building a modern system for management of human resources in the field of security.

\section{Instrument and Procedures}

A basic principle of situational analysis is „environmental scanning”, which is realized through a process of ,breaking down" the environment into certain factors and gathering information about the dynamics of their change in the direction of their influence. The purpose of their "scanning" is to determine with high reliability the sources of new opportunities 
and future threats to the security education and training system.

Bueno's model for the „Ten Forces” [1] describes a significantly more extensive and rich structure of the educational environment, but we offer an interpretation of the third of them, namely: $3^{\text {-th }}$ Level Level of existing competition. Actual competitors.

In order to analyze the competitive environment, the strength of each factor must be gauged. The combined impact of forces determines the intensity and the dynamics of competition. Studies of competitive environment provide important inputs in terms of assessment of the attractiveness of the system, the chances, the risks and the opportunities for transformation of its internal environment, the alternatives for choosing a competitive strategy.

Higher education stands out an extremely rich and diverse scientific and cultural asset. It plays a key role in the development of our society in the difficult path of realization of the idea of a Europe of knowledge.

\section{Data Analysis}

According to the Dictionary of Bulgarian synonyms, „teaching" is "education, science, education, doctrine, discipline, school," but teaching is also a process of understanding that facilitates alteration in behavior, skills and values. Under this definition of learning, the institutions of higher education in the system of security should achieve at least three results in this aspect, namely:

- 1. To cultivate substantial changes in trainees' mentality, perceptions and attitudes, for which the responsibility belongs entirely to the academic institution, which has the social responsibility not only to train but also to educate. Based on the results achieved so far, we can definitely believe that such institutions in the system of security are the place where young people receive education and guidance pertaining to their future through the values acquired in the process of training.

- 2. A continuous process of understanding is taking place, meaning that the learner can develop his or her own arguments concerning phenomena and facts.

- 3. To constantly share knowledge with and to build the skills of the learners, which are expressed in a specific competence.

Despite Bulgaria's membership in NATO for 13 years (since 2004) and in the EU 10 years (since 2007), Bulgarian university education, as a rule, still does not offer training in security in the context of the current security paradigm.

Reality gives us examples that provide proof of a successful, though still timid attempt to offer academic preparation for the growing need for international expertise at all levels of the security system.

Bulgarian university education is in the debt of the proposed security competencies in order to help develop the capacity for Euro-Atlantic security cooperation (in view of the internal and external security of the European Union).

The new features of the security environment determine the need for experts who are not only accustomed to rigorous analysis and the incessant sequence of actions to solve one or another task. The comprehensive approach to education and security training, confirming Aristotle's thought that „...what distinguishes knowledge from ignorance is the ability to be taught...'[2], would lead to the building of professionals that manage creativity and initiative toward rational and already regulated norms of behavior that are typical of the performance level.

\section{Results of Research}

The unfavorable state of the educational breakdown of the population (at present, 960,000 illiterate and without complete primary education) causes serious problems. Our system of education is retreating more and more from its traditional core functions of educating, teaching and spreading literacy, and as a 
result of some social groups have also irrevocably embarked on a process of alienation, and in the age of information society, we must not only talk about the fundamental necessity of education but also initiate the eradication of the growing illiteracy! The sector of public education is facing the challenge to enact the necessary structural changes with a view of the increase of its efficiency and adaptation to the dwindling demand for educational services.

In the light of our previous scientific developments and in helping the emerging „Strategic Review of ... (hope for security, not just for defense)", assuming that education based on the based scientific achievement is the added value to the system of security, we suggest that, in this future situational analysis, the education and training in the system of security finally find its worthwhile place.

Educational trends in the European Union (EU) influence the education and training in the system of security through Lisbonrelated processes and the creation of a European Education Space. The main points include the introduction of the European Qualifications Framework (EQF) and the complementary requirements for higher education and vocational training.

The European Union is experiencing a major problem with Bulgaria, indicated by the International Civic and Citizenship Education Study (ICCS): it reflects the ways in which young people are preparing to take their place in society. Obviously, with our current results, we cannot stop young Bulgarians from emigrating if they want to search for good education and good job prospects, and much has to be done to persuade the young generation to stay at home.

It seems that the native agenda for social development and that of the states or societies that we claim to be approaching differ not only in terms of speed but also in terms of direction. Our order of priorities (to build adequate links between education and the labor market in Europe 2020) requires responding to the challenges of the next 10 years: what education can we guarantee for sustainable, smart and inclusive growth?

In modern societies prosperity is achieved through education, while in our country people have been convinced that personal prosperity is achieved with some kind of a „miracle”! The amount of money does not appear to be the central issue in our education, but what to do with it. Economically advanced countries invest heavily in education, but in Bulgaria, it is perceived only as expenditure! And the difference really matters: investments are inseparably linked to the concerns about the quality of the education in order to ensure their decent return. Educational costs are always dominated by the concern to reduce them and a lot of compromises with quality seem acceptable. Our "democratic" negligence about the quality of education at the expense of our excessive efforts to cut corners take their toll: our students show a rapid decline among European countries in international comparative studies of functional literacy (PISA), civic competence (ICCS), and mathematical skills (TIMSS). The modern concept of knowledge management emphasizes the possibility of maximization of value and efficiency in the application of knowledge. Since information is constructed from data and knowledge is built from data and information, knowledge management includes three key building elements: data, information and knowledge. The main pillars of knowledge management remain people, processes and technologies. Other important components of knowledge management are the main components of the intellectual assets: data, information, knowledge and wisdom. Many knowledge management experts entertain the opinion that an effective knowledge management program accounts for around $80 \%$ for the human factor, $10 \%$ for processes and $10 \%$ for technology. Most experts agree that technology and technology-based solutions have importance, but they are actually a 
very small part of the overall effort to improve knowledge management, and an urgent need exists for replacement of the archaic hierarchical administrative format with more advanced network architecture. Most tasks in this area are related to the development of human and organizational culture to provide incentives and climate that fosters generation, sharing and spreading of knowledge.

\section{Conclusions}

The values that education carries and transmits into the system surface as the essential precondition for each person so that he or she will acquire an inherent capacity for specific responses to the stimuli of the emerging paradigm, containing a vast array of opinions and alternatives for their accomplishment. The explosion of technology, "conditio sine qua" non for the progress in science, education and research, is still transforming existential models, impacting not only positively some of its values. Gradually, the main factor and the ultimate resource becomes the human being with knowledge and qualities; not without a good reason, the great bulk of knowledge is generated in the field of human resource management. The factors influencing the processes also impose a new attitude towards knowledge, new demands upon education - through new technologies that overreach the power of human mind. Technologies are giving momentum to the post-modern society and are prompting a dramatic shift in lifestyles, behavioral patterns and system of values. But they call for criteria for evaluation not only of our past but also of our future.

The full conformity between tuition and research embodies the essence of university idea and proves that education and research belong together.

In a world that changes at such rates, without education one simply does not have the foundation to make the next step in the right direction.

\section{References}

[1] Bueno Campos, Eduardo, Curso b'sico de Economḱa de la Empresa, Pir'mide, Madrid, 1994, p. 222.

[2] Marinov Petar, Modern Challenges of Counter-Terrorism System Management, EastWest, pp. 78, Sofia, Bulgaria, 2017.

[3] Marinov Rumen, Exploring the capabilities of subdivisions in combat operations at critical times in urban terrain, Ph.D, dissertation, G.S. Rakovski National Defense College, Sofia, Bulgaria, 2012, pp. 112. 